\title{
Exploring the Meaning of Fun: A Missed Opportunity to Retain Underrep- resented Groups in Engineering?
}

\section{Jeannie Marie Purchase, Virginia Tech}

Jeannie Purchase is a PhD student in the Vecellio Construction Engineering and Management Program (VCEMP) in the Civil and Environmental Engineering Department at Virginia Tech. She is a New Horizon Scholar, Multicultural Academic Opportunities Program (MAOP) Graduate Scholar, and recipient of the Via Scholar Fellowship. Jeannie graduated with a B.S. in Biosystems Engineering from Clemson University. Her main research interests are public engagement for public infrastructure projects, sustainability education, and increasing diversity in STEM fields.

\section{Dr. Denise Rutledge Simmons P.E., Virginia Tech}

Denise R. Simmons, Ph.D., PE, LEED-AP, is an assistant professor in the Myers-Lawson School of Construction and in the Civil \& Environmental Engineering Department, and an affiliate faculty of the Department of Engineering Education at Virginia Polytechnic Institute and State University. She holds a B.S., M.S., and Ph.D. in civil engineering and a graduate certificate in engineering education - all from Clemson University. She is the 2016 recipient of Virginia Tech's College of Engineering Dean's Award for Outstanding New Assistant Professor and the Black Graduate Student Organization's Lisa Tabor Award for Community Service. Using deep insights from a fourteen-year industry career and her strengths as a systems thinker, she is now developing and disseminating empirically-grounded models and strategies for improved human competence, motivation, and learning as it relates to the civil engineering profession and the construction industry. She is a discipline-based education researcher who passionately pursues research to develop an agile, ethical, diverse construction workforce enabled to lead, design, and build sustainable, intelligent infrastructure. Her mission is to transform the construction workforce and sustain change. To this end, she undertakes research that enables her to influence postsecondary education and workplace learning pathways; instructional, diversity, recruitment, and retention strategies; and federal, state, local and institutional policies and practice and that result in professional competency in civil and construction engineering. 


\title{
Exploring the Meaning of Fun: A Missed Opportunity to Retain Underrepresented Groups in Engineering?
}

\begin{abstract}
Although more students from underrepresented groups are completing bachelor's degrees in engineering, these groups are still disproportionally represented in engineering professions. Recent research indicates that student engagement, both in and out of the classroom, can contribute to increased engagement and retention in engineering after college. This research sought to understand how "fun" manifests itself in the lives of underrepresented students and how "fun" is linked to student engagement. This case study used semi-structured interviews to investigate two students' (one Hispanic male and one White female) meaning of "fun" as they described their participation in in-class and out-of-class activities. The major theme that emerged was the importance of fun when participating in both in-class and out-of-class activities. Fun in out-of-class activities was associated with the development of a well-rounded engineer who can effectively manage the dynamics of work/life balance. The interview participants provided examples of fun in-class experiences that increased their levels of engagement through deeplearning instructional strategies. This research contributes a different perspective on student engagement in higher engineering education and supports the value of out-of-class activities and meaningful in-class activities in the development of underrepresented engineering students.
\end{abstract}

\section{Introduction}

In recent years, there has been increasing interest backed by research, public policy, national initiatives, and funding in increasing the number and diversity of engineering college graduates. ${ }^{1,2}$ According to the NSF National Center for Science and Engineering Statistics (2017), although there has been a gradual increase of students from underrepresented groups completing bachelor's degrees in engineering, underrepresented groups continue to disproportionally represent smaller percentages of engineering graduate degrees and employed professionals. $^{3}$

Whether focusing on retaining students or employees, studies have shown that engagement is a key indicator of retention. In his theory of student involvement, Astin (1984) defined student engagement as a student's academic commitment and application exhibited in the form of time and energy devoted to activities that are educationally purposeful. ${ }^{4}$ Many researchers have emphasized the importance of this concept of student engagement and suggest that enhancing engagement is essential to improving retention rates in higher education. ${ }^{5,6,7}$ The Corporate Leadership Council (CLC) defines employee engagement as "the extent to which employees commit to something or someone in their organization, how hard they work, and how long they stay as a result of that commitment." ${ }^{8}$ In a 2004 report, the CLC revealed that employees who were engaged at work were $20 \%$ more productive and were $87 \%$ less likely to leave the organization than employees who were not. ${ }^{8}$ Despite the importance of engagement in higher education and in industry, a recent Gallup-Purdue Index (2014) report involving a survey of over 30,000 college graduates revealed that only $30 \%$ of the United States' workforce is engaged at work. ${ }^{9}$ 
The Gallup-Purdue Index Report of 2014 also linked college students' in- and out-of-class engagement to workplace engagement and overall well-being after college. The Index Report used the following experimental and deep learning indicators to examine this connection: "I had an internship or job that allowed me to apply what I was learning in the classroom", "I worked on a project that took a semester or more to complete", and "I was extremely active in extracurricular activities and organizations in college". Graduates who exhibited each indicator were 1.8 to 2 times more likely to be engaged at work. ${ }^{9}$

Throughout their undergraduate career, engineering students have opportunities to become involved in several meaningful in- and out-of-class activities. For example, in the classroom, several engineering students might complete long-term projects prior to graduation to satisfy the design components (e.g., capstone design) of an engineering curriculum. ${ }^{10}$ Due to increasing recognition of their benefits, professional development opportunities such as internships, undergraduate research, and co-op opportunities are becoming more common amongst engineering students. When compared to other majors, however, engineering students are less likely to participate in out-of-class activities. ${ }^{11}$ Out-of-class activities are defined as any activity that occurs outside of the formal classroom, including curricular activities, co-curricular activities, and extracurricular activities. Research in engineering education has shown that outof-class activities are linked to numerous positive outcomes including students' professional, intellectual, and leadership development, as well as influencing students to pursue engineering careers after graduation. ${ }^{12,13}$ Some of the hesitation for pursuing out-of-class activities for engineering students include lack of time and motivation to participate in these activities. ${ }^{14}$

By understanding students' perceived benefits and motivations for pursuing out-of-class activities, we can begin to understand how these activities bolster student engagement in and outside of the classroom. In turn, this can inform policies and practices that may lead to increased retention rates of underrepresented groups in engineering. This case study was developed as a follow-up to a focus group that was part of a larger study designed to understand engineering undergraduate students' motivations for pursuing out-of-class activities. In this larger study, "fun" was identified as a major reason that underrepresented engineering undergraduate students chose to pursue out-of-class activities.

\section{Purpose}

The purpose of this research is to gain a deeper understanding of undergraduate engineering student engagement from the perspective of underrepresented groups. The two research questions used to achieve this purpose are: (1) how does "fun" manifest itself in the lives of underrepresented students? and (2) how is "fun" linked to student engagement in in-class and out-of-class activities? This case study investigated two students' (one Hispanic male and one White female) meanings of "fun" as they described their participation in in-class and out-of-class activities.

\section{Methods}


A case study analysis was conducted to address the above-stated research questions. In this section, study procedures are described including qualitative approaches, participant selection, data collection, data analysis, and theoretical frameworks used for interpretation.

\section{Qualitative approach}

A case study approach was selected for this study. Case studies involve collecting in-depth information about events or people in a particular setting and are particularly useful when exploring exceptional situations that call for a detailed investigation. ${ }^{15}$ Participants were identified for further study based on interesting and unique responses offered during focus groups conducted as part of a larger study exploring out-of-class activities of undergraduate engineering students. By using a case study approach, each participant's unique experiences and perspectives of "fun" in in- and out-of-class activities can be captured. While this method is restrictive in its generalizability, the information gained from case studies can help to inform and add understanding to the general phenomena under investigation. ${ }^{16}$

\section{Participant selection and description}

Two participants were chosen out of the ten students that participated in the initial focus group. These students were selected based on their responses in the previously introduced study; both participants described that they pursued and participated in out-of-class activities because the activities were fun, which prompted further investigation.

The first participant, Michael $^{\mathrm{A}}$, was a third-year manufacturing engineering student at a large, Hispanic Serving Institution (HSI) located in the southwestern United States. He identified himself as Hispanic/Latino and reported to be fairly involved in out-of-class activities. ${ }^{14}$ Some of these activities included participation in civic activities ${ }^{\mathrm{B}}$, engineering professional societies ${ }^{\mathrm{C}}$, engineering learning communities, practicum experiences ${ }^{\mathrm{D}}$, and undergraduate research.

Michael's decision-making related to out-of-class activity participation stood out for several reasons. He explained that he would not participate in an activity that was too tailored for him. For example, he identified as Hispanic/Latino but stated that he did not like groups that were specifically targeted for his ethnic group. He reported that targeted activities made him feel singled out and that he was in need of extra help simply because of his ethnicity. Also of interest, when describing his approach to deciding what activities to become involved in, Michael explained that he considers his "own convenience first":

Many of the reasons I am in organizations are personal reasons... I want to do something good for the organization, but it's also because, you know, it's MY ORGANIZATION so if my organization looks good, I LOOK good. It's not like I'm selfish or anything it's just you need to care about yourself first, then start worrying about everything else.

The second participant, Isabel, was a fourth-year chemical engineering student at a Predominantly White Institution (PWI) in a small, rural city in the southeastern United States. Isabel identified as White and reported to be fairly involved in out-of-class activities. ${ }^{14}$ Some of

\footnotetext{
${ }^{\text {A }}$ Pseudonyms are used to protect the identities of the participants.

${ }^{\mathrm{B}}$ Civic include community service and volunteering.

${ }^{\mathrm{C}}$ Engineering (or STEM) professional societies and groups like NSBE, SWE, ASCE, and activities associated with these groups.

D Practicum experiences include co-ops, internships, and field experiences.
} 
these activities included civic activities, practicum experiences, study abroad, and undergraduate research. Isabel was an interesting case because of the large amount of different activities that she participated in that did not pertain to academic organizations. She mentioned one of her main reasons for joining organizations was for the "fun" of the activity. Through the exploration of Isabel's usage of "fun," the researchers wished to gain a clearer and more accurate understanding of the idea of fun in undergraduate engineering education.

\section{Data Collection}

In preparation for each semi-structured interview, a separate interview guide was developed for each participant. These guides were produced after reviewing the focus group transcript and researching previous literature surrounding co-curricular involvement, culture, and the definition and understanding of "fun" as it relates to participation. For each interview guide, objectives were created and then mapped to the related questions as a feedback loop to ensure the desired topics would be addressed. Questions surrounding "fun" and culture were included in both interview guides. Each interview was conducted following interview guidelines laid out by Patton. ${ }^{17}$ The two interviews were audio recorded, and the interviewers also took notes.

\section{Data Analysis}

Data were analyzed using a form of whole text analysis as described by Corbin and Strauss. ${ }^{18}$ Audio recordings of the interviews were transcribed and inductively coded using the Creswell procedures illustrated in Table $1 .{ }^{19}$ After an initial round of coding, the researchers discussed initial codes and emerging categories. Multiple rounds of coding ensued until clear, coherent categories were identified; this iterative analysis often involved creating, deleting, and revising codes. Once codes and categories were finalized, they were organized into themes, which are further discussed in the next section.

Table 1: The coding process in inductive analysis

\begin{tabular}{|c|c|c|c|c|c|}
\hline $\begin{array}{c}\text { Steps to } \\
\text { inductive } \\
\text { coding }\end{array}$ & $\begin{array}{c}\text { Initial read } \\
\text { through text } \\
\quad \text { data }\end{array}$ & $\begin{array}{c}\text { Identify specific } \\
\text { segments of } \\
\text { information }\end{array}$ & $\begin{array}{c}\text { Label the } \\
\text { segments of } \\
\text { information with } \\
\text { codes }\end{array}$ & $\begin{array}{l}\text { Reduce overlap } \\
\text { and redundancy } \\
\text { among the codes }\end{array}$ & $\begin{array}{l}\text { Collapse codes } \\
\text { into themes }\end{array}$ \\
\hline $\begin{array}{l}\text { Creswell's } \\
\text { estimate }\end{array}$ & $\begin{array}{c}\text { Many pages } \\
\text { of text }\end{array}$ & $\begin{array}{c}\text { Many segments } \\
\text { of text }\end{array}$ & $30-40$ codes & $15-20$ codes & $5-7$ themes \\
\hline $\begin{array}{l}\text { Current } \\
\text { case study }\end{array}$ & 24 pages & 70 segments & $90-115$ codes & 20-30 codes & $\begin{array}{c}4 \text { themes (16 } \\
\text { categories and } \\
\text { sub-categories) }\end{array}$ \\
\hline
\end{tabular}

Note. Adapted from Creswell, 2012, Fig. 8.4, page 244.

\section{Theoretical Frameworks}

Astin's Student Involvement Theory is based on three main aspects of college: inputs, environment, and outputs. ${ }^{4}$ Out of those three aspects, educators can directly influence the environment the students encounter to promote desired outcomes. Tinto's Model of Student Departure divides the student's institutional environment into two divisions, the academic and 
the social systems, that both include formal and informal components. These systems lead to the crucial element of personal integration (academic and social), which determines whether a student will decide to depart from the institution; typically failure to integrate into either system leads to departure. ${ }^{20}$ While Tinto's model focuses on student departure from higher education in general, Meyer and Marx applied Tinto's model of institutional departure to students leaving engineering to switch to another discipline. ${ }^{21}$ The engineering students in their study exhibited the same integration barriers featured in Tinto's model that ultimately led to their decisions to switch majors. ${ }^{21}$ Like Tinto's model, Bean and Eaton's model emphasizes elements of academic and social integration but focuses on how environmental factors lead to student retention and not on student departure. ${ }^{22}$

Out-of-class activities fit into both Tinto's and Bean and Eaton's models by contributing to the social integration of a student. In Tinto's model, out-of-class activities are treated as a part of the formal social system and in Bean and Eaton's model they are nested within interactions promoting psychological processes and outcomes (e.g., reducing stress). ${ }^{20,22}$ Although these models separate students' academic and social integration experiences, we view student experiences as interdependent. Therefore, when analyzing the results of this study, we sought to understand how these experiences worked together to support the persistence of the student.

\section{Results}

The sections below explain the participants' perceived benefits of participating in out-of-class activities as they pertain to fun and how fun manifests itself within the curriculum. The participants indicated that some of the benefits of participating in out-of-class activities included: 1) a variety of new and different experiences results in personal growth and 2) experiencing more than engineering helps create work-life balance. The participants also provided examples of in-class experiences that were fun because they fostered deep-learning and increased levels of engagement. In addition, one of the participants presented an interesting viewpoint on contrasting motivations of students pursuing engineering for the "love of the subject" versus the "perks of the job."

For the purpose of this study, fun was defined by the participants. Although the students did not provide a specific definition for fun, they expressed their meaning of fun by providing examples of various experiences in both in- and out-of-class activities. One clear separation that was provided by both participants was that fun in in-class activities is not the same type of fun in outof-class activities. For example, Isabel relates fun in academic settings to engagement:

I guess academically; something is fun if it is interesting... It is engaging. There is a lot of interesting topics, but if they are not taught engagingly, then they may not seem very interesting.

Where Michael expresses, that fun in out-of-class experiences is more about enjoyment and relaxation:

I guess fun is like, to be able to enjoy yourself and like in a healthy way, right? But you know to be able to be able to release all the stress and just stop thinking about whatever you have to do when you get back home and just like enjoy yourself and have a good time. 
The participants' interpretations of fun laid the foundation for categorical themes developed in this section. Using an interpretive perspective, the researchers sought overlapping meanings and examples of fun provided by both participants to guide coding patterns and themes.

\section{Out-of-Class Activities}

Theme 1 - A variety of new and different experiences results in personal growth: When describing their favorite aspects of out-of-class activities, specifically outside of academic and engineering settings, Michael and Isabel emphasized how "fun" is meeting new people, going to different places, and doing a variety of different things. As they were reflecting, they explained how being exposed to these experiences helped shape their perspectives. Isabel provided an example of how she enjoys getting different points of view and learning from her interactions with the students from German club, making her a well-informed person:

In German club, sort of, [pause] a lot of the people in the foreign language department are also international studies majors so, like, talking to them about the news is always fun. Sort of getting their perspective, because they are usually more up on it than I am. And I am like, "Teach me. I want to learn" ... I like being a well-informed person, and I think meeting a lot of people helps you be a well-informed person.

When asked if the benefits of Michael's experiences when participating in multiple organizations outside of engineering could be achieved with one organization, he responded:

I don't think so because every organization is different, with different experiences, it is different mindsets and different kinds of people. So, for example, in the more engineering related activities it's more like my everyday friends, but when you open yourself to other organizations you meet lots of people that are not in engineering, and you can get more, I wouldn't say feedback, but more different voices, different mindsets that help you grow.

Theme 2 - Experiencing more than engineering helps create work-life balance: Based on statements made by Michael and Isabel, one perceived benefit of out-of-class activities is that they provide students with a "life" outside of engineering that they value and make schedule adjustments for, in order to participate.

When exploring potential out-of-class activities, Michael explained he purposely pursued ways to make friends outside of engineering: "I thought it was a better idea to take the time ... to get to know more people around the university rather than just the people around my major since I would have lots of time to get to meet them." Isabel expressed similar sentiments as she described meeting people from "cave club": "Engineering is the same people in all of your classes. So, it is nice to kind of go out and find other people in the university."

For Michael, venturing out of engineering provided an opportunity to balance the "work" side of life with more leisure aspects. Michael described how his experiences with engineering organizations differ from other organizations:

So, it's really different because when you are in engineering and in society, it's about professional ethics and all this kind of engineering related stuff, STEM careers and all of that. And when you go to another organization that is more of an entertainment or social kind of deal, so I think it is really important to have that balance. 
Although Isabel understood the average engineering student's pursuit to fill their resume with academic and engineering societies, she also believed that employers also value activities not work related:

Because companies want you to be able to do a work-life balance. Sort of [pause] have a healthy life outside of your job [laughs]. That makes a better employee. Being able to show in college that you did extracurriculars that weren't related to engineering sort of helps communicate that you can do that when you have a job too. You are not going to just live your job. And that's, that's important.

Their interactions with professors inspired Michael and Isabel's beliefs on the importance of having "fun" and having a life outside of engineering. For example,

Michael talked about his professors wanting students to also have fun:

I think they value both [engineering and non-engineering activities] because they really want students to get involved and they want students to be having fun. Because in the end, college is supposed to be the greatest years of your life, you're not supposed to be suffering. So, they do believe that you should be networking, you should be studying, but also you should be relaxing and having fun while you're doing it.

In addition to gaining different perspectives, the participants believed these experiences helped them become well-rounded individuals. Their experiences have contributed to the development of skills that will be beneficial in the work world. For example, both students credited their experiences to improving their interpersonal skills with diverse groups, and Isabel explicitly expressed that meticulous time management is crucial for her to manage her course work and out-of-class activities.

\section{Curricular Context}

Theme 3 - Deep learning experiences increase student engagement: When the participants were asked to recall when they considered engineering fun, the participants provided examples that were tied to deep learning experiences. For this study, deep learning experiences are defined as experiences of instructional strategies ${ }^{\mathrm{E}}$ that promoted participants' adoption of a deep approach to learning. ${ }^{23}$ These experiences were described in three categories: reducing the pressure and stress of evaluation, incorporating real world applications, and accessing hands on opportunities.

Isabel and Michael presented the idea that their courses were more fun and supportive of learning when evaluation pressure and stress were reduced. Michael explained that learning in academia could be more enjoyable when taking the "grade out of the equation." He went on to say, "Because in the end, I "like' my classes, but the only thing I don't like is that I am being graded every single day, and I have to get certain scores to be okay." Both students explained some of the benefits associated with removing the evaluative pressures. For example, Isabel expressed how she decided to audit a course in cryptography systems even though she did not have a computer coding background. She shared:

\footnotetext{
${ }^{\mathrm{E}}$ Felder et al. ${ }^{23}$ outlines eight features of instruction that constructively align with students' adoption of a deep approach to learning and provide instruction strategies that achieve reflect these features (e.g. project/problem-based learning, active learning, cooperative learning)
} 
I was not super great at computer coding. So, I elected to audit that class. And it's a lot of fun. Taking out the element of, like, having to worry about homework has made it a lot more engaging ... Not everyone is great at coding, but you can still understand the topics.

Isabel described a similar pressure-free environment in a math course in which the professor graded homework for completeness rather than correctness.

So, that really [pause] frees you to like do the homework as best you can and not worried that, like, you didn't get it right because he will, like go over it. He cares more that you have attempted it then like your correctness on it.

Michael and Isabel described engineering as fun and engaging when real-world examples were used when learning concepts in the classroom. For example, Isabel expressed that:

Seeing how what you are learning actually, applies in the real world [makes classes more engaging]. Because then, suddenly, your class work seems more valued because you know you are going to use it later. You know you might need to use it later.

Similarly, Michael explained that he values real world applications because ".... when you are learning about the content, you can actually see it reflected on something that you are actually aware of." He goes on to say that real world applications "... make the class or curriculum relevant, so the people who take it or the students who graduate from that curriculum are able to understand their surroundings and use what they learned to grow or to expand their surroundings."

Hands-on opportunities such as lab experiences provided students with the opportunities to apply the concepts learned in class. Michael described that engineering as more engaging and fun when he can actively participate in his courses:

...like its fun when engineering becomes instead something like a class, you make it something more hands on, so anything like you are actually doing something, or you are experiencing something new ... It's something I enjoy and have fun with.

Isabel's positive experiences with labs and hands-on work have even inspired her and her classmates to advocate for adding lab components to other courses because she feels they are "kind of dry" without them:

Because it's [pause] when you are doing an industrial degree program, it can be hard to do hands on work. ...They are like "oh!" and you are using things that you have learned in class but on actual equipment now, and you are like, "Ah! This is much more interesting!" And we are actually sort of arguing that process controls should actually have a lab aspect for that reason. Because process controls is kind of dry without it.

Theme 4 - Contrasting primary motivations: Love of subject vs. perks of the job: One interesting finding that emerged from this case study was the rationale concerning student motivations for pursuing and persisting in engineering, as exhibited by Isabel. This viewpoint emerged as she described her contrasting views on the behaviors, attitudes, and outcomes of students who pursue and persist in engineering. When discussing different experiences throughout her degree program, one of the words Isabel commonly used to describe them was "interesting." When asked to elaborate on why she found her program interesting, Isabel 
explained: I am of the opinion that if you are not working on something you find interesting, you are going to stop enjoying your job pretty soon. Like job, happiness is just how interested you are in the topic.

Isabel explained that regardless of the complexity of a course or the difficulty of the program, her department continuously promoted the importance of her feelings and interests towards the degree to ensure that she was "enjoying classes" and "finding the work interesting" throughout her program. Isabel explained how students in chemical engineering could "easily drop out" of the program and major in chemistry if they do not like the major. She explains how her department is "supportive" if a student decides to switch:

And the department is really supportive of that. They are like "No. Please don't do a degree that you hate in the end because that's going to be your job opportunities related to your degree. And so, if you get a degree in a field that you don't really like then you are not going to get a job that you like." So, I think the department is pretty good about making sure that you do like the degree to some extent.

She goes on to further explained why her department wants students to "really enjoy" their major:

Because it is a hard degree program and uh it shows through if you don't really enjoy the subject. And uh [pause] like [pause] it reflects poorly on the department if you, like, have students who don't really care about it. Because it shows through in your work and like right now we are doing design work for a company and so if you're not interested in your project, the company gets that feeling, and it looks bad for University.

Throughout her interview, Isabel provided examples of pursuing in- and out-of-class opportunities because she enjoyed the topics. For example, she decided to double major in math due to her continued interest in the subject after completing her minor course requirements, stating that she "missed learning new math."

In addition to expressing the importance of finding her major interesting, Isabel explained some of the consequences of students pursuing engineering for just the perks of the career (e.g. highpaying job). She explained that one of the pros of engineering being marketed as a high paying job is the influx of applicants; however, not all of those students remain in engineering:

And I think there is nothing wrong with getting a degree because you want a high paying job [laughs]... Whenever engineering is in the top ten [highest paying job], they get a lot more applicants than other programs. It's like "ok." And then you spend the next two years weeding out to the people who will at least stick around.

Instead of only marketing the materialistic aspects of engineering such as salary and the "flashy and fun" parts that attract more students, Isabel suggested departments should be more "honest" about the rigor of the programs. She explained that some students who pursue engineering solely for career perks might end up hating it.

I think departments should be a little more honest when they advertise what their degree programs are. Not just show them the flashy, fun stuff, but be like, "no. It is hard." And tell them what they are getting into. Um because I have seen a lot of sophomores that are like "I hate engineering. I don't want to do this anymore". And it's like, "Ok. We can help 
you get out of the program. There's nothing wrong with that." ... [In engineering] you can do a lot of really cool stuff, but you have to do a lot of grunt work to get there. It's not all super awesome and relaxed all the time.

\section{Discussion}

This case study revealed that for underrepresented engineering students "fun" manifests itself differently when discussing in-class and out-of-class activities. Seeking fun in out-of-class activities helps students to establish a life outside of engineering and provides exposure to a variety of new and different experiences that result in personal growth. Having fun during inclass activities was related to the students' experiences of high levels of engagement, where the examples provided were associated with deep learning exercises.

Based on this study, we suggest that out-of-class activities support students' overall well-being, which can increase their persistence in engineering. Additionally, deep learning experiences may increase student engagement. The combination of the in- and out-of-class activities may enhance the undergraduate experience and increase levels of retention of underrepresented groups in engineering.

The 2014 Gallup-Purdue Index report argues that colleges and universities have room to improve in terms of providing a quality education; only $30 \%$ of the U.S. graduates are engaged at work, and $29 \%$ of graduates are not thriving in any of the five areas of well-being: purpose, financial, social, community, and physical. Although there is no way to help students achieve high wellbeing in all areas directly, "institutions can help provide their students with goals that are ultimately more fulfilling than income alone".

From experiences analyzed in this study, it was found that participation in out-of-class activities played an integral role in helping distinguish student/work life as separate, but related spheres. Whether these activities helped the students relieve stress, increase physical activity, build community, or engage in an active social life, participation in out-of-class activities helped to contribute to their overall well-being. Both students emphasized the importance of making connections and gaining exposure. In a related research study, Pierrakos and colleagues showed that students who persisted in engineering were more likely to make connections with peers and faculty as compared to those who switched majors. ${ }^{24}$ That study also revealed that individuals who left engineering were less likely to participate in out-of-class activities than students who stayed. $^{24,25}$

Other studies have focused on in-class participation. The Approaches and Study Skill Inventory for Students (ASSIST) survey analyzed student motivations for studying and various learning styles. ${ }^{26,27}$ The patterns revealed from the survey were used to establish three categories of student study approaches: deep, strategic, and surface. Deep learning is associated with higher levels of engagement and independent thinking. Some of the factors that contributed to this approach to learning were seeking meaning and relating ideas. The surface apathetic approach included factors related to syllabus boundedness and fear of failure, while the strategic approach lies in between these extremes with factors related to time management and achievement motivation. ${ }^{26,27}$ When Michael and Isabel explained the benefits of removing the pressure of 
evaluation they alluded to the freedom to explore and learn in environments that encouraged understanding, a characteristic of deep learning. ${ }^{27}$ Therefore, removing the pressure of evaluations made in-class activities more fun and helped to increase student engagement by shifting student learning approaches from surface to deep level learning.

Michael and Isabel emphasized the importance of having hands-on and real-world application problems. They expressed how these activities helped to "bring engineering to life" and made them see how they would use the technical information they learned in class. One of the major criticisms of engineering that prevents underrepresented groups from entering and staying in engineering is the lack of societal relevance of the discipline. ${ }^{28,29,30}$ There has been a large push to incorporate more of the real-world experiences similar to those described by the participants of this study within engineering education.

Isabel criticized the engineering discipline for promoting only the "flashy" aspects and not being upfront about the difficulty of the program. Her criticisms are consistent with one of the deterring factors of engineering, featured in the NSF Engineering Workforce Report, that engineering is sold as a "means" to a job rather than a means to a solid education. ${ }^{28,29}$ Also, her sentiments and behaviors associated with her love for the subjects of engineering and math are consistent with motivations of deep learning engagement research, also featured in the ASSIST survey mentioned above. ${ }^{26}$

\section{Implications}

The main implication of this study is the suggestion that retention of underrepresented students in engineering may be linked to participation in out-of-class activities, thus resulting in a need to increase student participation in out-of-class activities. One way support engineering faculty can support this goal is to serve as examples for students, by sharing their hobbies or life outside of work with students. This proved to be a particularly impactful experience for one of the participants in this study; Michael interpreted his professors sharing their lives as granting him permission to "have fun" too. Additionally, engineering faculty and career services can express the benefits associated with out-of-class activities, including emphasizing activities that are not associated with engineering. Typically, first-year college students refrain from participating in out-of-class activities to focus on school. However, the desire to participate in out-of-class activities led Isabel to employ meticulous time management, which fostered her ability to achieve and maintain a high GPA, participate in multiple out-of-class activities, and obtain internships, research opportunities, and admission into a graduate program in Europe.

The MUSIC Model by Brett Jones consists of components that instructors can use when designing courses in order motivate students to engage in learning. ${ }^{31}$ The five components of the MUSIC model are empowerment, usefulness, success, interests, and caring. Michael and Isabel exhibited the effects of these motivational factors described by Jones. ${ }^{31}$ Professors can begin to employ MUSIC strategies that can lead to increased engagement. For example, usefulness can be exhibited by professors by working to bridge the relevance of the course content to societal impacts or real-world applications. By including how the content can be applied in industry, professors can increase the importance/usefulness of the content to the students leading to higher engagement levels. The interest component can be used when recruiting students as faculty can 
market the engineering disciplines based on societal impacts (e.g., designing and maintaining foundations of society through water, transportation, communication, etc.) in addition to the perks of the job (e.g., high salaries). An example of exhibiting the caring component was demonstrated by Isabel's professors when they encouraged her to pursue a major she "enjoyed."

\section{Conclusion}

This research contributes a different perspective on engineering engagement in higher education and supports the value of out-of-class activities in the development of underrepresented engineering students. This exploratory study suggests that fun in higher engineering education can be an avenue for retention in engineering disciplines. Analysis of perceptions of two interview participants suggests that the idea of "fun" in the lives of underrepresented, undergraduate engineering students is a complex, yet relevant topic for future research with the potential to increase graduation and retention rates.

This study suggests some directions for future study. While this exploratory case study focused on "fun" in the lives of two students broadly, future research could include investigating this phenomenon more specifically in either in-class or out-of-class settings. This will improve the understanding of the relationship between "fun" and student engagement, and how they link to career satisfaction. For the participants in this exploratory study, out-of-class activities helped them balance different aspects of well-being and remain engaged with their work. Further research can explore how these activities help students build the capacity to "bounce-back" from high-stress work environments.

\section{Acknowledgements}

The authors would like to gratefully acknowledge the National Science Foundation for their support of this work under the CAREER grant \#EE-1351156. Any opinions, findings, conclusions, or recommendations expressed in this poster are those of the authors and do not necessarily reflect the views of the National Science Foundation. The authors also wish to acknowledge Alison W. Bowers for her contributions made to this study.

\section{References}

1. Olson, S., \& Riordan, D. G. (2012). Engage to Excel: Producing One Million Additional College Graduates with Degrees in Science, Technology, Engineering, and Mathematics. Report to the President. Executive Office of the President.

2. Didion, C., Fortenberry, N. L., \& Cady, E. (2013). Colloquy on Minority Males in Science, Technology, Engineering, and Mathematics: National Academies Press.

3. National Science Foundation, N. C. f. S. a. E. S. (2017). Women, Minorities, and Persons with Disabilities in Science and Engineering: 2017. Retrieved from Arlington, VA: www.nsf.gov/statistics/wmpd

4. Astin, A. W. (1984). Student involvement: A developmental theory for higher education. Journal of college student personnel, 25(4), 297-308.

5. Crosling, G., Heagney, M., \& Thomas, L. (2009). Improving student retention in higher education: Improving teaching and learning. Australian Universities' Review, 51(2), 9-18. 
6. McInnis, C., James, R. H., \& McNaught, C. (1995). First year on campus: Diversity in the initial experiences of Australian undergraduates: AGPS [for] Centre for the Study of Higher Education, University of Melbourne.

7. Chen, H. L., Lattuca, L. R., \& Hamilton, E. R. (2008). Conceptualizing engagement: Contributions of faculty to student engagement in engineering. Journal of Engineering Education, 97(3), 339-353.

8. Council, C. L. (2004). Driving performance and retention through employee engagement. Retrieved from

9. Gallup Inc., G.-P. I. (2014). Great Jobs Great Lives The 2014 Gallup-Purdue Index Report. Retrieved from Washington, DC:

10. Howe, S. (2010). Where are we now? Statistics on capstone courses nationwide. Advances in Engineering Education, 2(1).

11. Lichtenstein, G., McCormick, A. C., Sheppard, S. D., \& Puma, J. (2010). Comparing the undergraduate experience of engineers to all other majors: Significant differences are programmatic. Journal of Engineering Education, 99(4), 305-317.

12. Meyers, K., Pieronek, C. F., \& Mcwilliams, L. H. (2012). Engineering student involvement. Paper presented at the American Society for Engineering Education.

13. Simmons, D. R., Tendhar, C., Yu, R., Vance, E., \& Amelink, C. (2015). Developing the Postsecondary Student Engagement Survey (PosSES) to Measure Undergraduate Engineering Students' Out of Class Involvement. Paper presented at the ASEE Annual Conference and Exposition, Seattle, WA.

14. Simmons, D. R., \& Yu, R. (2015). Conducting a Q Study to Refine and Develop New Measures of Engineering Student Co-Curricular Involvement. Paper presented at the Research in Engineering Education Symposium 2015, Dublin, Ireland.

15. Stake, R. E. (1995). The art of case study research: Sage.

16. Creswell, J. W. (2012). Qualitative inquiry and research design: Choosing among five approaches: Sage publications.

17. Patton, M. Q. (1987). How to use qualitative methods in evaluation: Sage.

18. Corbin, J., \& Strauss, A. (2014). Basic of qualitative research: Techniques and procedures for developing Grounded Theory. 2014: Thousand Oaks, CA: Sage.

19. Creswell, J. W. (2012). Educational research: Planning, conducting, and evaluating quantitative and qualitative research (4th ed.). Boston, MA: Pearson Education Inc.

20. Tinto, V. (1993). Leaving College: Rethinking the Causes and Cures of Student Attrition.

21. Meyer, M., \& Marx, S. (2014). Engineering dropouts: A qualitative examination of why undergraduates leave engineering. Journal of Engineering Education, 103(4), 525-548.

22. Bean, J., \& Eaton, S. B. (2001). The psychology underlying successful retention practices. Journal of College Student Retention: Research, Theory \& Practice, 3(1), 73-89.

23. Felder, R. M., \& Brent, R. (2005). Understanding student differences. Journal of Engineering Education, 94(1), 57-72.

24. Pierrakos, O., Beam, T. K., Constantz, J., Johri, A., \& Anderson, R. (2009). On the development of a professional identity: Engineering persisters vs engineering switchers. Paper presented at the Frontiers in Education Conference, 2009. FIE'09. 39th IEEE.

25. Hein, G. L., Bunker, K. J., Onder, N., Rebb, R. R., Brown, L. E., \& Bohmann, L. J. (2012). University studies of student persistence in engineering and computer science. Paper presented at the American Society for Engineering Education.

26. Entwistle, N. (2000). Promoting deep learning through teaching and assessment: conceptual frameworks and educational contexts. Paper presented at the TLRP conference, Leicester.

27. Entwistle, N., Tait, H., \& McCune, V. (2000). Patterns of response to approaches to studying inventory across contrasting groups and contexts. European Journal of Psychology of Education, 15(1), 33-48.

28. Blue, C., Blevins, L., Carriere, P., Gabriele, G., Kemnitzer, S., Rao, V., \& Ulsoy, G. (2005). The Engineering Workforce: Current State, Issues, and Recommendations: Final Report to the Assistant Director of Engineering. National Science Foundation.

29. Busch-Vishniac, I. J., \& Jarosz, J. P. (2004). Can diversity in the undergraduate engineering population be enhanced through curricular change? Journal of Women and Minorities in Science and Engineering, 10(3).

30. Goodman, I. F. (2002). Final Report of the Women's Experiences in College Engineering (WECE) Project. Online Submission.

31. Jones, B. D. (2009). Motivating students to engage in learning: The MUSIC model of academic motivation. International Journal of Teaching and Learning in Higher Education, 21(2), 272-285. 